\title{
ON THE OCCURRENCE OF FITS IN SYRINGOMYELIA.
}

\author{
By J. P. MARTIN, Loxdox.
}

MucH as the symptoms of syringomyelia have been studied, the occurrence of fits in the course of the disease seems to have received little attention. In Schlesinger's classical monograph, ${ }^{6}$ it is true, a paragraph, very much to the point, is devoted to their description, but fits are not mentioned among the symptoms of syringomyelia in any of the English textbooks of medicine or neurology, even when rarer features, such as Charcot's joints and spontaneous fracture of bones, receive recognition. For this neglect several reasons may be assigned : (1) A fit is a transient symptom not often personally observed by the physician ; (2) fits are not usually inquired for during the examination, and if the patient speaks of them they are regarded as purely incidental epileptic phenomena ; (3) their occurrence is not demanded by the anatomical findings.

Among the cases of syringomyelia, probably not more than twenty, certainly not more than thirty in all, which I have seen during the last three years, there have been four in which occasional fits occurred, and I believe that these seizures of syringomyelic patients have a certain significance in the symptomatology of the disease.

\section{NATURE OF THE ATTACKS.}

In November, 1921, I happened to see the first of my patients have one of his seizures while in hospital. He had complained for several days of severe headache and of pain in the back of the neck, and one morning, without further warning, he was seen to become rigid; all his muscles were tonically contracted, the limbs were in extension, the hands tightly clenched, the forearms pronated and moving into a position of slight hyperpronation, trismus caused a grinding noise of his teeth, there was no actual arching of the back, but the head, which had been raised, was thrust back into the pillows; breathing was interrupted by the spasm, and the patient began to get cyanosed; from the moment of onset he seemed quite unconscious, and as the spasm relaxed after about thirty seconds, he slowly recovered consciousness, and in a few minutes had returned to his former condition. Immediately after the attack the pupils were active to light, and the other reflexes showed no change from 
their usual, pathological, form. The patient's mental state all that day, both before and after the attack, was less bright than usual.

This seizure seemed to me clinically indistinguishable from the 'tonic fits' which are seen in some cases of cerebellar tumour, in some cases of hydrocephalus, and in certain other morbid states. During his stay of five months in hospital the patient had three fits of this nature, all accompanied by loss of consciousness.

A second patient, while at her work, 'fell down,' and does not remember being taken home; a fellow-worker said she had had a fit, but that she did not 'struggle' at all, or give a cry or 'froth' at the mouth.

The fits of a third patient are thus described by his mother : " $\mathrm{He}$ just goes stiff all over and throws his head back. He does not struggle or kick, but after the stiffness he becomes quite limp. He has always become unconscious."

$\mathrm{Up}$ and down the literature there are numerous allusions to fits in syringomyelic patients, but in not many cases have the seizures actually been described. Schlesinger ${ }^{6}$ says in the paragraph to which $I$ have already referred: "Among the general symptoms are to be included generalized tonic or clonic fits. ... They are often accompanied by loss of consciousness ; in many cases, however, and this observation $\mathrm{I}$ would emphasize, consciousness is completely retained, and the patients $\mathbb{Q}$ complain loudly of the muscle contractions which are often very painful. The spasms may involve the whole body and so recall tetanus. In one of my patients I have several times had the opportunity of seeing a generalized spasm of this kind, in which trismus and opisthotonus occurred; the patient usually did not lose consciousness until spasm of the glottis and severe disturbance of the circulation set in." In the case to which he presumably refers (his No. XII.), attacks are recorded on two successive days, and again a week later ; on the first day the patient lost consciousness as the attacks came on, but on the second he remained fully conscious though the fits persisted for ten minutes.

In the report of a case by $\mathrm{A}$. Westphal ${ }^{10}$ it is stated that " the tonic contractions affect also the musculature of the back and lead to attacks with pronounced opisthotonus ; by involvement of the abdominal and chest muscles in the spasm interruption of breathing is brought about."

Bullard and 'Thomas ${ }^{1}$ described in their patient " a spasm in which the head was thrown back, there were no movements of the extremities, the eyes were open and consciousness was retained."

Schultze ${ }^{7}$ recorded in one of his cases of syringomyclia the observation of a tonic fit with trismus and opisthotonus.

Tonic seizures are the only fits which I have found described (or seen) in syringomyelia; Schlesinger ${ }^{6}$ (loc. cit.) mentions the word ' clonic,' but he does not state that he had ever seen a clonic fit in the 
discase, nor does he give any description of clonic fits or a report of, or reference to, any case in which they occurred. While, therefore, in rare cases there may be an intercurrent true epilepsy, if in the history of a case of syringomyelia a fit is mentioned and no description of it is forthcoming there is a presumption that it has been tonic in nature. The tonic fit, with or without loss of consciousness, is the kind of seizure that may perhaps find a place in the symptomatology of the disease.

Premonitory Symptoms.- In two of my patients, and in one of them repeatedly, fits were preceded for several davs by severe headache and pain in the back of the neck. In Westphal's ${ }^{10}$ case there was much complaint of headache, but the author does not say whether the headache occurred just before the scizures. In the case reported by Bullard and Thomas ${ }^{1}$ intense headaches and romiting had been present for a long time, and three or four weeks before the fit attacks of dizziness began to occur.

Exciting Causes.- Though no exciting causes can be definitely assigned, the exertion of effort seems to have a precipitating effect. One of my patients had her only fit when she had almost reached the top of a flight of stairs. Another, who had previously had a seizure, returning to hospital to visit another patient, apparently had a fit while going up the fourth flight of stairs; she fell to the bottom of that flight and fractured the base of her skull. In the other two cases attacks occurred during active periods of the disease while the patients were at rest in bed, but it may be that if they had been allowed to exert themselves their seizures would have been more frequent.

Phase of the Disease in which Fits occurred.-Examination of the case histories given below shows that all four paticnts became worse very soon after the occurrence of their seizures. The first patient, who had previously been able to go about, had a fit in the street, afterwards gradually became weaker in his lower limbs, and at the end of six weeks was totally unable to walk; during his stay in hospital he had three fits, and at that time he was becoming more and more paralyzed. The second patient had a fit while at work; after it, her right leg gradually became weak and stiff, and at the end of two months she was taken into hospital. The third patient had two fits in one night before he had any symptoms of syringomyelia, but within a few weeks he was unable to raise his arms above his head, and within six months they were almost completely paralyzed. The fourth patient, too, had a seizure before she had any definite symptoms of syringomyelia, but within two months she began to suffer from pain in the right arm and the arm soon wasted.

I am not inclined to think that the fits had any aggravating or exciting influence on the syringomyelia, for then the consequences would have been more immediate, but rather that they occurred at a time when the disease was especially active. In the cases of Westphal ${ }^{10}$ and of Bullard 
and Thomas ${ }^{1}$ the seizures took place during periods of rapid deterioration, and in Schlesinger's ${ }^{6}$ case they occurred shortly before death, when the symptoms were fast becoming worse.

Frequency.-It is difficult to estimate the fraction of cases of syringomyelia in which fits occur. As I have said, I have met with them in four cases out of a total of less than thirty. Schlesinger ${ }^{6}$ reports them in two cases (possibly three) out of forty-nine. The proportion is probably in the neighbourhood of 10 per cent. They are only to be expected in those cases which pass through a more or less acute stage.

As regards the frequency of attacks in any individual patient, this is subject to great variation, but I believe it may be taken as a general rule that they are infrequent and are limited to periods of active progression of the syringomyelia. One of my patients had three seizures in five months, but only one attack was known of in the two years before that. Another had four attacks, in pairs, with three months between the two pairs, and was then free from them for about a year. A third patient, ailing slightly for ten years, only reported two attacks in all, and the fourth, in whom the disease had been in evidence for three years, had only had a single (initial) attack.

\section{THE PROBABLE MODE OF CAUSATION OF THE FITS.}

As an explanation of the occurrence of these tonic seizures, two varieties of theory suggest themselves and require to be examined : (1) the fits might either be a 'focal' symptom depending on the involvement of a particular portion of the central nervous system in the syringomyelic process, or (2) they might be due to the action on the tonic centres of a 'general' mechanism, such as increased pressure of, or the presence of toxic substances in, the cerebrospinal fluid.

In the theories of the first group involvement, presumably irritation, of the pons by the gliosis has been suspected. Schlesinger, while expressing the greatest doubt on this theory, noted that fits had been reported "mostly in cases where there was advanced bulbar involvement and only rarely as a transitory initial phenomenon."

Now, in none of the four cases I am discussing was there any clinical indication that even the bulb was affected. It is true that in three of them nystagmus was present, but this may be due to affection of the cervical cord, and cannot be regarded as an unequivocal bulbar sign. In none of the cases was the tongue or palate affected, and in none was any sensory loss found on the face. It cannot, therefore, be said that in any of them the bulb was extensively involved, and I think it very improbable that in any of them gliosis, showing so little evidence of its presence in the medulla, should have extended as far upwards as the pons. Further, the weight of pathological evidence is entirely against such frequent affection of the pons. 
In the cases I have mentioned from the literature, direct pathological evidence is available. In Schlesinger's ${ }^{6}$ case (XII.) there was no gliosis or cavitation in the medulla, and the pons was intact; in the case of Bullard and Thomas ${ }^{1}$ the gliosis extended as high as the middle of the medulla, but the pons again was undamaged. In Westphal's 10 case, however, the pons was affected ; though the only evidence clinically of syringobulbia had been the presence of fibrillary twitchings in the tongue, it was found at autopsy that there was a narrow, median fissure which extended, with some interruptions, throughout the bulb and into the pons.

The converse argument, for what it is worth, is that in Spiller's ${ }^{8}$ well-known case, where the pons was extensively affected, and the gliosis had reached as high as the cerebral hemispheres, no fits are recorded as having occurred.

There is thus no stable basis for the theory that the fits are dependent on pontine involvement in the gliosis. A fortiori, they are not dependent on the involvement of any part above the pons. Below the pons no centres for the general regulation of tonus are known to exist, and if such centres did exist in the medulla and their irritation could give rise to fits, there is still the fact that fits occurred in at least one case in which the medulla was found intact.

The theories of the first class cannot, then, satisfactorily account for the occurrence of these tonic seizures. There remains the second group.

In all the four or five instances of which definite histories are available, fits in my patients were associated with persistent headache, usually with pain in the back of the neck, and in one case with vomiting -symptoms suggestive of an increase of intracranial pressure. In the case of Bullard and Thomas ${ }^{1}$ the fits were associated with headache, vomiting and papillœedema, and at the postmortem examination there was found, as well as the syringomyelia, marked dilatation of the ventricles and of the iter of Sylvius. In Schlesinger's ${ }^{6}$ case optic atrophy was present, and internal hydrocephalus was among the findings at the autopsy. But in the case of Westphal, ${ }^{10}$ in which the seizures were limited to a period of a few months about two and a half years before death, no dilatation of the ventricles was observed post mortem.

Again, these tonic seizures seem identical with those which occur in certain cases of cerebellar tumour or of basic meningitis, in which hydrocephalus is almost a constant finding.

Finally, hydrocephalus, unlike pontine gliosis, is common in syringomyelia. Schlesinger reported some degree of it in six out of the eight cases in his book in which the brain was examined after death, and many other writers, e.g., Grund, ${ }^{2}$ Hinsdale, ${ }^{4}$ Saxer, ${ }^{5}$ Taylor, Greenfield and Martin, ${ }^{9}$ have recorded a similar finding in smaller numbers of 
cases. In addition Hassin ${ }^{3}$ has drawn attention to the high pressure of the fluid within the cord observed at operation in cases of syringomyelia.

It therefore seems probable, in spite of Westphal's $\mathbf{1 0}$ negative finding, that the occurrence of fits in syringomyelia is associated with, and is a manifestation of, internal hydrocephalus. Moreover, since long intervals, with remission of headache, may occur between the seizures, and chronic hydrocephalus may be found after death, it is likely that the fits are associated with short, acute exacerbations of the chronic hydrocephalus.

If the fits be indeed due to hydrocephalus, their occurrence during or just before periods of aggravation of the syringomyelic symptoms points to an acute exacerbation of hydrocephalus at those times in certain cases of the disease; this fact should be taken into account in considering the pathogenesis of syringomyelia.

\section{SHORT REPORTS OF CASES.}

Case 1.-E. H., male, aged nineteen, admitted to the National Hospital, Queen Square, on September 15, 1921, under the care of Dr. Risien Russell ; discharged February 6, 1922.

He complained of inability to walk and of spasms of the lower limbs, in which the knees were drawn up towards the abdomen.

There was no history of nervous disease in the family.

The patient " had never been a bright child," according to his mother. He had had no serious illnesses. His eyes had always twitched from infancy and his eyesight had been poor.

Present Illness.-About November or December, 1919, the patient began to suffer from pain in the back of the neck and between the shoulder blades; it would come on suddenly, often at night, last about twelve hours and pass off gradually. About May, 1920, "he kept on dropping things" from his hands. A month or six weeks later he began to "stumble about." IDuring August of that year he went to camp with the Territorials, and when marching he noticed that his left foot dragged; several times he fell. When he came home from camp he was still walking unsteadily and suffering from pains in the back of the neck; he began to get thinner : he used to fall frequently. On September 26 he had a fit in the street one evening, and remembered nothing more until he woke up at home the next morning about six oclock. Six weeks later he became unable to stand and was admitted to an infirmary. He remained there nine months, and during that time his lower limbs became drawn up.

Examination.-A pale, delicate-looking youth, poorly nourished. Wears glasses (high myopia).

Cranial Nerves.-Optic dises normal ; visual fields full; pupils normal.

External ocular movements full, but accompanied by gross nystagmus. Other cranial nerve functions normal.

Motor Functions.-In the upper limbs muscular power was much im- 

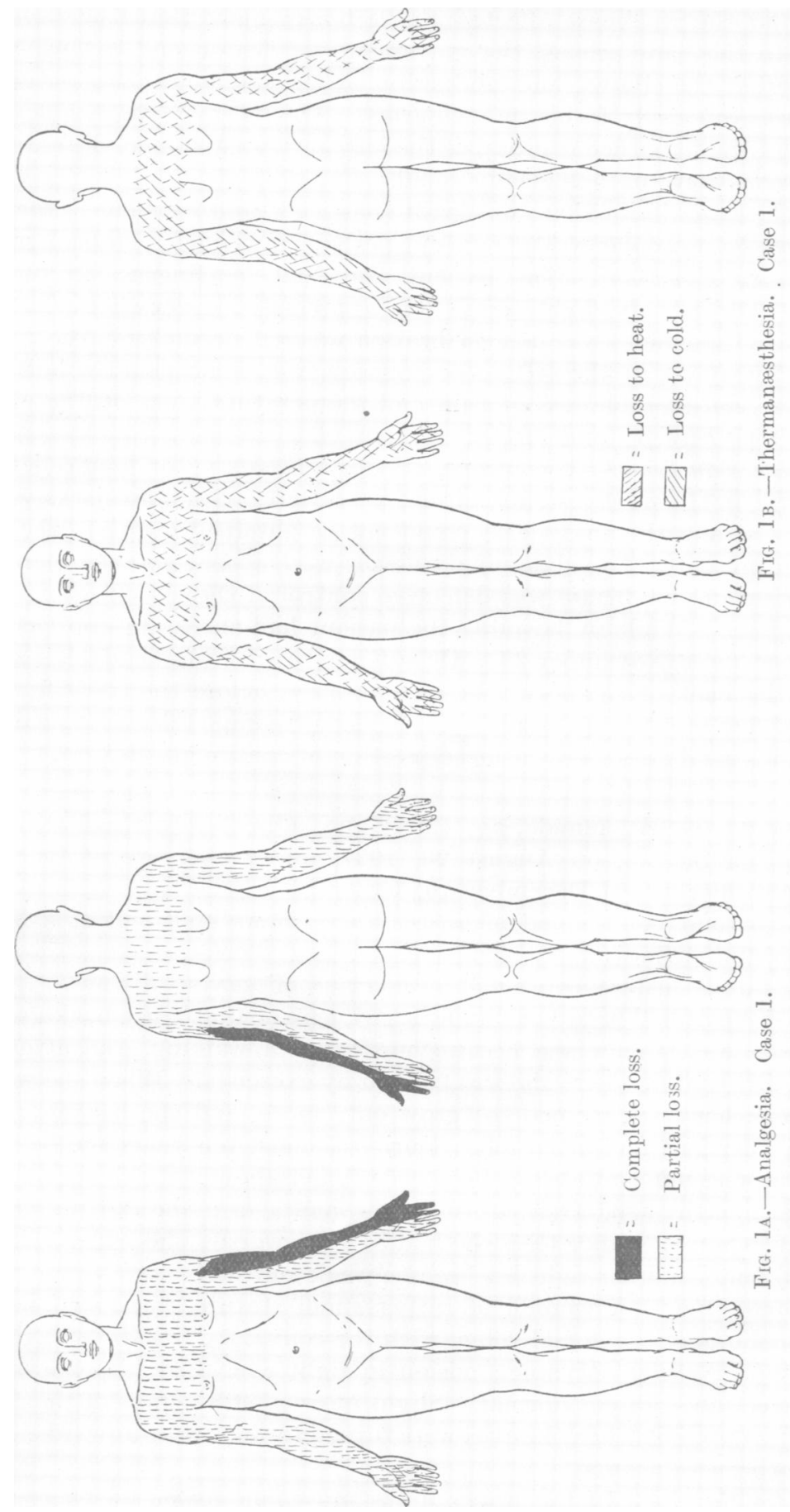
paired and the weakness affected the left arm more than the right. This applied to the hand-grasps, the movements of flexion and extension at the wrists and at the elbows, and abduction at the shoulders; the action of the triceps was especially feeble in both arms. The interosseous muscles of both hands and the hypothenar group of the left were wasted, and the extensors of the forearms were pathologically small.

In the lower limbs there was great spasticity, and frequent flexor spasms. There was no muscular wasting except perhaps in the left peroneal group.

Sensory Functions.-The patient said that his fingers felt numb and swollen. Objectively, light touch was appreciated everywhere, but on the lower limbs topognosis was poor ; vibration was felt normally in the right arm, but hardly at all in the left. Stercognosis was very poor in both hands. There was considerable loss of pain and temperature sense on the chest and left arm (see Figs. $1 \mathrm{~A}$ and $1 \mathrm{~B}$ ).

Reflex Functions.-The biceps, triceps and supinator longus jerks were very feeble in the right arm and absent in the left. The knee-jerks were both exaggerated, and the ankle-jerks could not be obtained owing to the amount of spasm present. The abdominal reflexes were absent and the plantar both strongly extensor. There was defective control of the vesical sphincter.

Progress.-While in hospital the patient had three fits-on October 17, November 3 and November 25. He suffered much from headaches and from pain -in the back of the neck; he also vomited before the third fit. In the course of five months his arms became almost completely paralyzed and his lower limbs gradually went into the position of continuous flexion.

CASE 2.-G. W., female, age thirty-one, admitted to the National Hospital, Queen Square, on August 23, 1921, under the care of the late Dr. Saunders ; discharged December 15, 1921.

The patient complained of unsteadiness in walking and of a feeling of weakness and stiffness in the right leg.

The family history contained no mention of nervous disease.

The patient had been healthy as a girl, except that " her back grew out." Before she was twenty she became unsteady in walking, and attended St. Thomas's Hospital, where she was treated by exercises. When she was about twenty-one her back seemed to 'grow out' more, and she became more unsteady in her gait and often fell. During the last ten years she had become slightly worse, but had always been able to get about.

Two months ago, while at work, she had a fit; she did not remember being taken home. Since then she had become worse ; she felt as "if she had no life in her," and her right leg became weak and stiff.

Examination.-A woman of rather small stature, very well nourished. Kyphoscoliosis of the dorsal spine, with the convexity towards the right.

Cranial Nerces.-Myopic; vision in right eye, $3 / 60$; in the left, 6/18, with correction. Pupils normal. Slight internal strabismus of the right eye. Nystagmus present when the eyes were turned to the left or upwards. Cranial nerves otherwise normal.

Motor System.-In the upper limbs muscular power was better on the 

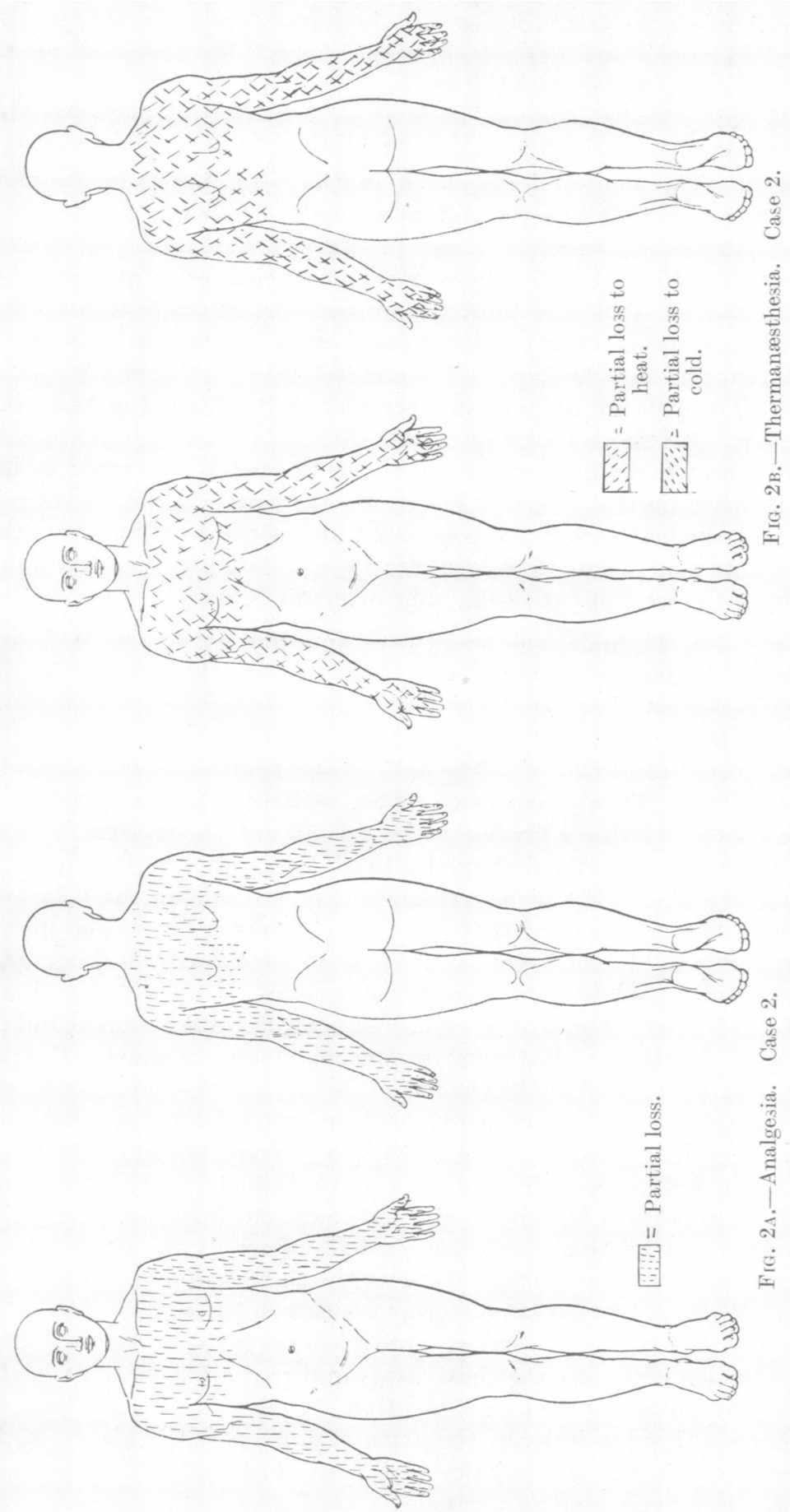
right side than on the left : at the left shoulder all movements were fecble; the left-hand grasp was weaker than the right. No apparent wasting of muscles.

In the lower limbs all movements of good power ; definite spasticity in the right limb.

Reflexes.-The tendon jerks, both in the arms and legs, were brisk; plantar reflexes both extensor; abdominal reflexes absent.

Defective bladder control; delay in micturition.

Sensation.--Light touch felt everywhere except over an area covering the right scapula. Pain and temperature not normally appreciated over the areas indicated on the charts (Figs. $2 \mathrm{~A}$ and $2 \mathrm{~B}$ ). Vibration sense absent in the right arm and in both legs, and decreased in the left arm.

Gait.-The patient did not lift her feet well, staggering to cither side indifferently. Romberg's sign positive.

About three months after her discharge the patient returned to hospital to visit another patient. When going up the fourth flight of stairs she is believed to have had a fit. She was found unconscious at the bottom of that flight and remained unconscious for three days. An $x$-ray photograph showed a fracture of the base of the skull. She afterwards made a good recovery.

CASE 3.-J. T., male, age twenty-seven, admitted to the National Hospital, Queen Square, on February 2, 1922, under the care of Dr. Aldren Turner ; discharged April 13, 1922.

Family History.-Negative.

History of Present Illness.-The patient was healthy, as far as was known, until July, 1921. Then, during one night, without any warning, he had two fits while asleep. Within a few weeks he "could not use his arms properly" ; he was not able to raise them above his head as before. In October, 192i, he had two more fits. His arms gradually became weaker, and by the time he was admitted to hospital they were almost powerless. The fingers had begun to 'close in' to the palms, and he could not straighten them out.

Examination.-A well-developed young man.

Cranial Nerves.-Optic discs and fundi healthy. Pupils equal and regular, with normal reactions. External ocular movements normal. Coarse, irregular nystagmus on looking to the left.

Motor System.-.-The hand-grasp weak on both sides, but weaker on the left than on the right. Flexion and extension movements at wrist and elbow very weak in both arms. Patient unable to abduct the arms to more than about 45 degrees from his sides. Supraspinati and infraspinati of both sides showed advanced wasting; deltoids wasted, especially the right ; the biceps and triceps of both arms wasted, those of the right arm more so than those of the left. No loss of power or muscular wasting in the lower limbs.

Sensory System.--No loss of appreciation of light touch. Pain and temperature not felt over the chest, arms and part of the back (sec Figs. 3A and $3 \mathrm{~B})$. No gross loss of sense of position.

Reflexes.-Tendon jerks in the arms absent on both sides. Knec-jorks exaggerated, and the ankle-jerks brisk on both sides. Plantar reflexes extensor. Sphincter control normal. 

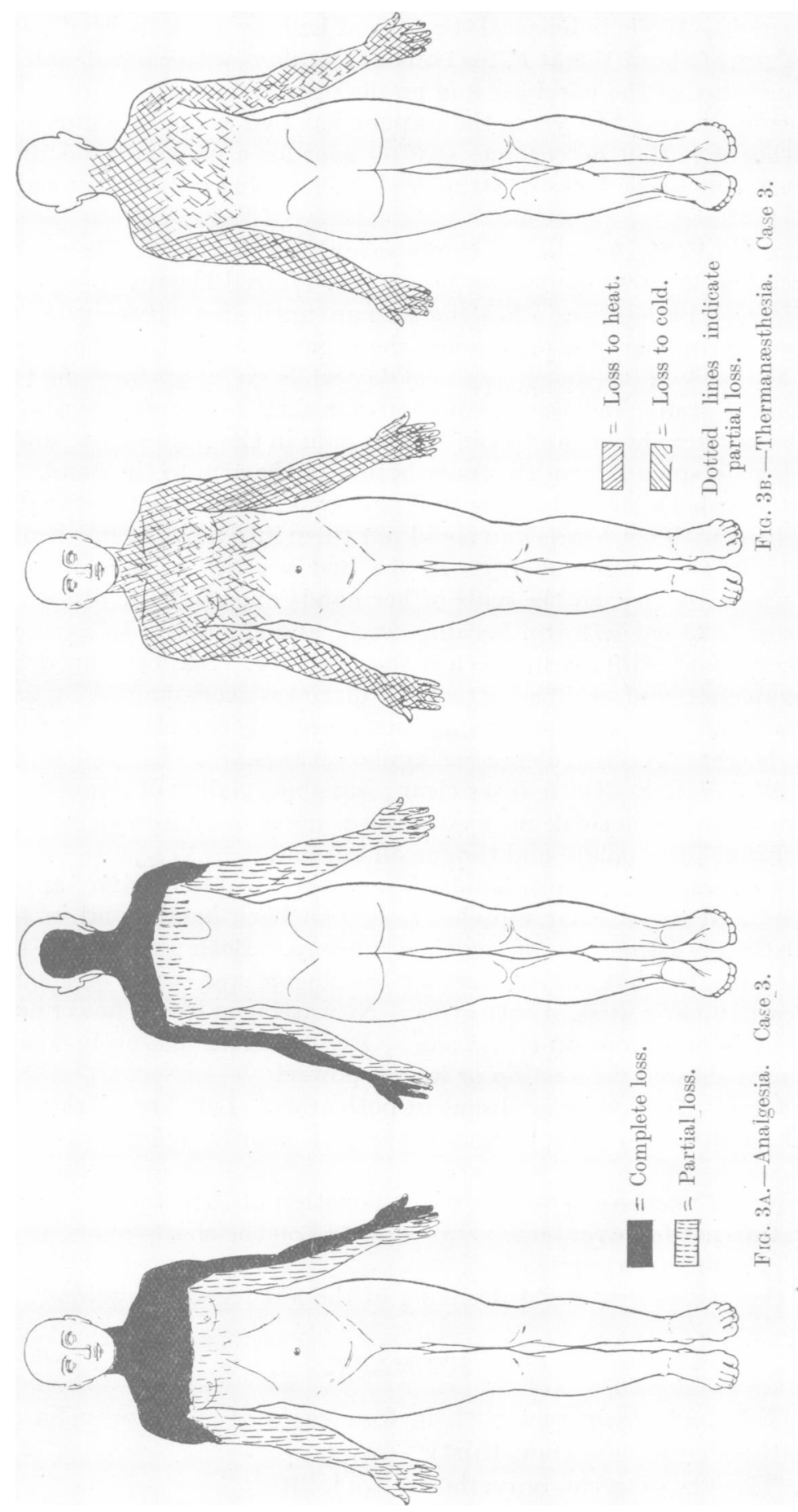
Progress. - While in hospital the patient had several attacks of fever, with temperature of about $103 \cdot 5^{\circ} \mathbf{F}$. for two or three days with each attack. There was no advance of the paralysis and no fits occurred.

During the last two years the patient has had seven or eight slight fits. His mother says that he becomes stiff all over for a moment, and throws his head back, but never kicks or struggles : he has always become unconscious.

CASE 4.-E. K., female, age thirty-seven, admitted to St. Mary's Hospital on November 22, 1923, under the care of Dr. Wilfred Harris.

History.--Patient was a healthy woman until about three years ago ; at that time, during her first pregnancy, she began to suffer from headaches and pain in the back of the neck, and one day while going upstairs she had a fit, fell down the stairs, and was unconscious for three hours afterwards. About two months later she began to suffer from pain in the right elbow, and after a time this pain spread down the inner border of the arm to the hand. During the next year both hands became thin and weak, and she noticed that she did not feel heat with her hands and could put them into a hot oven when she was baking. In the winter of 1922-23 she had a series of painless whitlows, during which she lost all the nails of her hands one after the other. In the summer of 1923 her left arm became worse and she began to have a feeling of weakness and stiffness in the left foot and leg. She continued to suffer from headaches, and also had attacks of dizziness accompanied by nausea.

Examination.-A well-nourished woman of pale complexion and less than average height. A slight degree of kyphoscoliosis.

Cranial Neries.--Optic dises clear; no abnormality of pupils; external ocular movements normal, no nystagmus; no sensory loss on face; movements of jaw, face, palate and tongue all normal.

Motor Functions.-Both hands showed the 'main-en-griffe' appearance. Interossei and hypothenar muscles wasted in both hands, and in the right hand distinct wasting also of the thenar group. Both grips weak, the right more so than the left. Extensors of the fingers and wrist of good power. Flexor carpi ulnaris weak in both arms. No wasting or loss of power noticeable in the biceps or triceps on either side. Right deltoid distinctly weak. The lower limbs showed no wasting or loss of power.

Reflexes.--Tendon jerks absent in both arms. Left knee-jerk and anklejerk exaggerated, the right normal ; the left plantar reflex extensor, right flexor.

Sensory Functions.-No loss of appreciation of light touch, but pain and temperature not felt over large areas indicated on the charts (Figs. 4A $_{\mathrm{A}}$ and 4B). No loss of sphincter control.

In the gait a very slight dragging of the left leg was apparent.

\section{SUMMARY.}

1. Fits have been met with in four cases of syringomyelia out of a total estimated at less than thirty.

2. The fits of syringomyelia are tonic fits. 

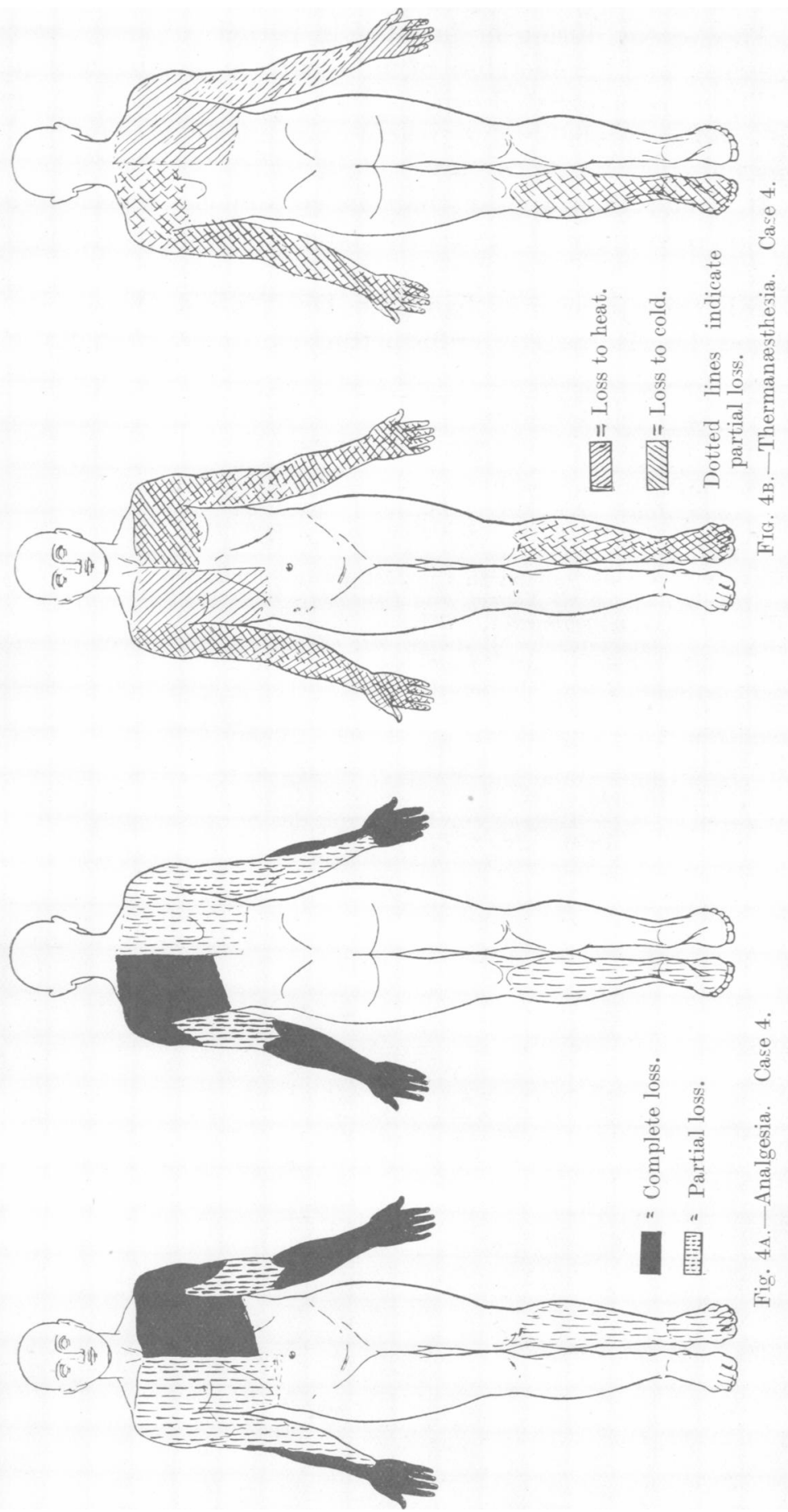
3. They occur during or just before periods of active progression of the disease, and are therefore of unfavourable prognostic significance.

4. They are associated with symptoms of increased intracranial pressure, and are probably due to acute exacerbations of internal hydrocephalus.

5. It would thus appear that in certain cases periods of rapid aggravation of syringomyelia are associated with exacerbations of hydrocephalus.

I wish to express my thanks to Dr. Wilfred Harris, Dr. Risien Russell and Dr. Aldren Turner for permission to make use of their cases.

\section{REFERENCES.}

1 BULLARD and THomas, "A case of syringomyelia with unusual symptoms," Amer. Jour. Med. Sci., 1896, lxvii, 265.

2 (inoxi, "Zur Kenntnis der Syringomyelie," Deut. Zeits. f. Nervenheilli., 1908, xxiv, 304.

3 HAssix, "A contribution to the histopathology and histogene-is of syringomyelia," Arch. of Neurol. and P'sychiat., 1920, iii, 130.

4 Hissdale, Syringomyelia, 1897.

s SAXER, "Anatomische Beiträge zur Kenntnis der sogenannten Syringomvelie," Beit. «. path. Anat., xx.

6 Sintesiscier, Die Syringomyelie, 1902, 191.

7 Sinclize, Quoted by Sichlesinger (6).

s Sipll.ter, "An unusual case of syringonyelia," Brit. Med. Jour., 1906, ii, 1017 .

9 TAYlOR, GREenfIELD and MARTIx, "Two cases of syringomyelia," Brain, 1922, xlv, 323.

10 Westryat, A., "Beitrag zur Lehre von der Syringomyelie," Deut. Arch. $f$. klin. Med., 1899 , lxiv, 35.). 